\title{
A Linguistic Ethnography of Teacher Talk in an English for Medical Purposes Classroom
}

https://doi.org/10.33806/ijaes2000.20.1.3

\author{
Omar Ali Al-Smadi, Radzuwan Ab Rashid and Dheif Allah Hussain \\ Altamimi \\ ${ }^{1}$ Al-Ghad International Colleges for Applied Medical Sciences, Saudi \\ Arabia. \\ ${ }^{2}$ Universiti Sultan Zainal Abidin, Malaysia. \\ ${ }^{3}$ Tabuk University, Saudi Arabia
}

\begin{abstract}
This study is a linguistic ethnographic investigation of the characteristics of teacher talk in an English for Medical Purposes (EMP) class at one of the medical colleges in the kingdom of Saudi Arabia. Teacher talk is an important element in classroom interaction and it has direct and indirect implications on the students' learning. In classroom interaction, students and teachers are in a state of dynamic interactions. If not carried out tactfully, classroom interactions can affect learning process in several ways such as failure to engage in learning process and inappropriate teacher's instructions. This study employed an eclectic qualitative methodology which incorporates principles of Linguistic Ethnography. Data generation took place in the entire Semester One of the academic years 2017/2018. The data in this study were obtained from 10 classroom observations. Informal chat with the teacher was carried out towards the end of each observation session to get further clarification of what had happened during the observation. The teacher talk was found to be dominant in classroom interactions. The teacher talk had high frequency of self-repetition and paraphrasing. The teacher accepted students' ideas and avoided criticism. The teacher praised the students and offered both positive and negative feedback. This study concludes that teacher talk still serves as a useful source for classroom input despite the buzz of learner-centered approach which demands reduced teacher talk in the classroom.
\end{abstract}

Keywords: classroom discourse, discourse analysis, English for medical purposes

\section{Introduction}

English is a universal language and it is the language of science and medicine. English is also considered the most important factor in getting a career as well as pursuing educational goals (Sankar and Kumar 2016; Radzuwan, Rahman, Shireena, and Kamariah 2017). In Saudi Arabia, the only foreign language taught in public schools is English which starts in Grade Four (aged 10 to 18), while in private schools English is taught as early as Grade One (aged 6 to 18). As students move to university level, English is mainly used as the language of instruction, especially within medicine and health sciences schools. Therefore, the importance of English is vital for those who intend to study in medical and 
healthcare institutions. This implies the necessity of those students to be proficient in written and spoken English. Students must write their reports in English, discuss medical cases in English and take formal examinations which is also in English. This results in a demand to study and instruct English in medical area for both general and specific purposes. This study aims to answer the following question: What are the characteristics of teacher talk in the English for medical purposes course?

\section{Literature review}

Some research reveal that most English classrooms are still teacher-dominant and students only respond to teacher. In their research on teacher talk, Behtash and Azarnia (2015) reported that teacher talk was dominant in classroom; that is $75 \%$ of classroom talk was occupied by the teacher whereas the students have less than $20 \%$ of classroom talk. Szendori (2010) conducted a study in ESP classroom which indicated a parallel result, an average of $71 \%$ of classroom talk was taken by the teacher while $29 \%$ of the classroom talk was filled by the students talk. These research findings support former research led by Chaudron (1988) Long (1996) and Zaid, Safawati, Zakaria, Mohd, Radzuwan, Ismail and Nur (2016).

In English as a foreign language classroom, English teachers' talk furnishes students' input where there is limited exposure to English language outside the classroom context. Recent studies in EFL context affirm the importance of teacher talk in classroom interactions and that the teacher talk provides the students with a comprehensible input (Winarti 2017, Lucero and Rouse 2017, Irmayani and Rachmajanti 2017; Ab Rashid 2018).

In their study of teacher talk in EMP context, Al-Smadi and Rashid (2019) found that teacher talk is modified and simplified to suit the students' level. Paraphrasing and repetition were rich in teacher talk to clarify medical language and to ensure input comprehensibility. The teacher modified classroom talk to stimulate classroom interactions, avoid confusion, and ensure input comprehensibility. Modifying talk was subject to students' level and was seen necessary to achieve clarity of the course content as well as facilitating learning process.

Classroom teachers simplify and modify their talk to effectively engage students with different levels of proficiency and suit lesson objectives (Al-Smadi and Rashid 2017). Teachers in classroom involve a large amount of questions as they are main instruments for classroom evaluation and instruction; the use of questions engages students in classroom interactions (Al-Zahrani and Al-Bargi 2017). Teacher's feedback has an impact on student involvement in classroom talk (Abu Shakra 2005). In classroom interactions, teachers accept students' answers and ideas and offer correction where necessary (Al-Zahrani and Al-Bargi 2017). Also, teachers accept students' ideas and use their language during interaction (Jarad 2009). Teacher talk patterns includes but not limited to joking, correcting students' answers without rejection, offering directions, praising and encouraging, and asking questions (Winarti 2017). 
In accordance with Long's (1996) interactional hypothesis, Ginting (2017) claims that teachers' interactions through their talk excite learners' acquisition of target language. In her study of classroom interactions, Ginting (2017) employed Sinclair's and Coulthard's (1975) IRF model for the analysis of classroom discourse, in particular, the teachers' opening moves. The analysis of interactions between the teacher and the students revealed that the teacher opening moves were implemented through elicitation, directing, informing, checking, reinforcing, listing and re-initiation. Also, she found that the teacher used questions to lead interactions in the classroom and more than half of the lessons were occupied by the question-answer structure. Ginting (2017) also claimed that the success of lessons is mainly dependent on questioning and follow-up made by the teacher.

\section{Methodology}

This empirical study aims to investigate the characteristics of teacher talk in EMP class. Data generation took place in the entire Semester One of the academic years 2017/2018. The data were collected through classroom observations. 10 classroom observations were carried out. When necessary, every time the classroom observation took place, informal chat with the teacher was carried out to get further clarification of what had happened during the observation.

The teacher involved in this study is a native Arab aged 37 with over 15 years of English language teaching experience. He has a Master degree in Teaching English as a Foreign Language and he has attended several workshops in developing excellence of teaching.

The observed class in this study consists of 20 male students, aged from 18 to 22. Based on the placement test offered at the beginning of the semester, the students are on level A2 according to the Common European Framework of Reference for language learning. Students who are at this level (A2) have the ability to deal with simple, straightforward information and begin to express oneself in familiar contexts.

All the recorded data were transcribed. The following codes were used in the transcription: (CO1, M10) refers to classroom observation number one, minute ten and (IC) refers to informal chats. Names of the students are replaced by (S1, $\mathrm{S} 2, \mathrm{~S} 3$ etcetera) and the name of the teacher is replaced by (T).

For analyzing data, generic resources like jokes, instructions, educational performs like modelling, and questioning were examined. Adopting social, cultural and functional linguistic knowledge, the analysis was grounded on the researchers' interpretation of what create such resources. Regarding the use of rhetoric, for instance, repetition and metaphor which serve the rhetorical function were examined.

\section{Findings}

\subsection{The amount of teacher talk}

The teacher talk was primary during most of the classroom time. $60-73 \%$ of classroom talk goes to teacher. The percentage is worked out based on the 
calculation of the number of utterances made by teacher and students. This percentage aligns with what Allwright and Bailey (1991), and Winarti (2017) stated regarding the proportion of teacher talk in classroom. One possible justification for this goes to the nature of EMP content, that is, most of the language taught in classroom is new to student and they have no prior knowledge regarding it which results in most cases to offer opportunities for students to respond to specific questions asked by teacher. Also, the level of students determines to a large extent the amount of teacher talk, i.e. the higher the level of the students suggests more students' talking time whereas the lower the level of the students demands the teacher to talk more in order to secure comprehension.

\subsection{Praise and encouragement}

Throughout the observation, praises and encouragement appeared to be one of the characteristics in the teacher talk. The teacher encouraged and praised students regularly. The teacher always offered words for praising such as 'Brilliant', 'Excellent' 'Good job' 'Very good'. Interestingly, in all the lessons observed, the teacher encouraged students to speak and practice target language in ways supporting their confident and reducing anxiety. The following transcript illustrates how the teacher supported the students' confidence.

Extract 4.1

1 T: It is ok if you make mistakes. Mistakes are natural part of

2 Learning. We are here to learn. No one is perfect.

(CO1, M 20).

The teacher made it clear for the students that mistakes are natural and common and he does not mind anyone making mistakes which is evident in saying it is ok if you make mistakes (line 1). Also, the use of footing we (line 1) position the teacher at the same level of his students. After receiving such encouragement, the students were observed to be more willing to speak and taking part in learning activities. They felt freer due to friendly classroom atmosphere in which risk taking is encouraged and face-threatening acts were lessened.

As said earlier, the teacher used words such as "Brilliant", "Excellent" "Good job" for praising individual student. The teacher also frequently praised and encouraged the whole class. The following transcript illustrates how the teacher praised the whole class.

Extract 4.2

T: Keep going... you are the best group I have ever had.

\subsection{Jokes}

$(\mathrm{CO} 2, \mathrm{M} 27)$.

It was found that the teacher used jokes in all afternoon classes as a tool to encourage learning. In these afternoon classes, jokes appeared at the beginning and middle of lessons. The students in the afternoon classes were tired, less energetic and less focused. The teacher used jokes as a tool to create an energetic atmosphere where he can achieve lesson goals, make sure that students are concentrating and encourage participation. 
The following transcript illustrates the teacher's use of joke in classroom; particularly at the beginning of classroom.

Extract 4.3

1 T: S3 you would be a great dancer except for two things

2 S3: What they are?

3 T: Your tall skinny feet.

(CO5, M2).

In previous extract, the teacher saw one of students dancing when he entered the classroom. The teacher took this incidence to tell a joke and made everyone in class laugh. The teacher in this way avoided side talks among students and used the joke to get students' attention and a sign to begin the lesson.

As stated above, jokes appeared at beginning and middle of lesson. The following transcript illustrates the use of jokes at the middle of lesson.

Extract 4.4

1 T: One patient came to the doctor telling him that whenever he

2 drinks tea his eyes hurt. The doctor told him to take out the spoon

3 from the cup before he starts drinking.

(CO3, M33).

The topic of lesson was about describing symptoms. The teacher told this joke to create a pleasant atmosphere for students to laugh and encourage their participation about describing and talking about symptoms.

The teacher expressed in one of informal chats that he did not want student to be bored and consequently affect lesson objectives. The teacher said: "I do not mind spending five minutes joking or listening to jokes in classroom with students. It will help me achieve my goals easier and faster" (IC, 2). The teacher's use of humor and jokes in classroom as a learning tool aligns with Reddington and Waring (2015) and Bell (2013) who conceptualize jokes as forms of linguistics creativity, enhancing classroom language learning and support participation.

\subsection{Accepting and using students' ideas}

The teacher regularly welcomes ideas made by students' and even used them in his talk. This practice was seen when summarizing, elaborating, modifying or clarifying students' responses. The following transcript illustrates how the teacher used one of the student's ideas to elaborate further on the student's idea when they were discussing codes for visiting patients at hospital.

Extract 4.5

1 S11: not bringing flowers

2 T: That's brilliant... It is important not to bring flowers into ward

3 as patient might be allergic to flowers...

4 Good job S11.

$(\mathrm{CO} 2, \mathrm{M} 16)$.

The teacher used the student's idea and offered justification for it (lines 2, 3 ). In this sense, the teacher confirmed the student's answer, offered explanation of why it is important not to bring flowers when visiting patients and praised the student for this idea (line 4). 
Another example of using students' ideas appeared when the teacher and the students were talking about putting patients at ease.

Extract 4.6

$1 \quad$ S4: Treat patient as a family

2 T: Bravo S4... It is important to treat patients as a family member

3 or close friend... This will make them happy and relaxed

4 S7: Imagine you the patient

5 T: Excellent idea student $7 \ldots$ It is essential to treat your patients

6 as you wish to be treated yourself.

(CO2, M13).

In this excerpt, the teacher used students' ideas and elaborated on how important they are (lines 2, 3, 5, 6). By doing so, the teacher accepts the ideas, clarifies the ideas and offers praise to support student's participation and motivate the students to take part in learning activities. Sometimes the comment on the teacher's feedback is in the past tense and sometimes in the present. Both are correct as long one is used consistently.

\subsection{Offering instructions and modelling}

It was found in the observation that instructions were often supported when the teacher requested students to work in pairs or in groups. The teacher always made sure that students understand very well what is needed by offering clear instructions, checking comprehension and modelling. By offering clear instruction, students were seen having fewer questions about what they are expected to do.

The teacher set an excellent model for students to follow. The teacher was well-informed, prepared and established clear expectations for the students. Regarding his teaching, the teacher models all the activities in front of class before asking students to work on supplemented task. The following transcript illustrates how the teacher offered clear instruction and model the answer for the students.

Extract 4.7

1 T: You guys are going to work in pairs practicing asking and

2 answering questions about patient details. For example, student A

3 will ask student B: Who is your GP? Student B replies: Dr. 4

4 Adam Sheller. OK... Is that clear? Another example... student A:

5 What is your occupation? Student B: construction worker.

(CO1, M30).

In this extract, the teacher modelled the answer for the students (line 3). Also, the teacher used the question Is that clear? (Line 4) to check comprehension. The teacher also offered second example to ensure understanding (Line 4, 5). After receiving clear instructions and modelling, it was noted that the students were less anxious, knew exactly what they are expected to do and therefore save class time as students have no questions to ask regarding their comprehension of task. 


\subsection{Avoiding criticism on students' behavior}

The teacher avoided criticizing students especially their performance. The teacher expressed in one informal chat that he does not want to demotivate students, set boundaries between him and the students and create an autocratic classroom atmosphere (IC, 2). Regarding students' responses and answers, the teacher chose to group mistakes and address them at the end of lesson (Extract 4.10 in next section explains how the teacher did that), while spontaneous mistakes were dealt with nicely after repeating students' answers. The following transcript illustrates how the teacher corrected the mistake after repeating the student's answer.

Extract 4.8

$1 \quad$ S: We use needle to fill the tube with blood.

2 T: We use syringe to fill tube with blood... Syringe is used to fill 3 tube with blood, OK... syringe.

$(\mathrm{CO} 5, \mathrm{M} 31)$.

The teacher corrected student's answer from needle to syringe and repeated the correct answer which is syringe (three times) and it is used to fill blood in a tube (line 2). The teacher used repetition and comprehension check (line 3) as a tool to correct the inaccurate answer made by student. It can be seen that the teacher corrected the student's answer indirectly. The teacher did not say this is wrong or refuse the answer. Also, the teacher did not yell or scold the student for not differentiating between needle and syringe. Rather, the teacher repeated the correct answer three times and asked for comprehension by saying $O k$ (line 3 ) to make sure that the whole class comprehended the difference between needle and syringe and minimize chances of future misuse of both words trough repetition.

\subsection{Giving feedback}

Offering feedback is an essential role of teacher in classroom. Also, timing for giving appropriate feedback is important in language learning. The teacher in this study offered feedback very nicely in supportive warm ways that would never discourage students to participate. The following transcript illustrates how the teacher offered feedback to the students.
Extract 4.9
1 T: Is the patient dependent or independent?
2 S12: Patient independent
3 T: How do you know that?
4 S12: Patient can go toilet alone
5 T: Excellent S12... Independent patients can do daily activities
6 and routines without any help.

(CO7, M39).

In previous extract, the teacher and students were talking about evaluating patients' level of independence. The student answered the question correctly (line 2 ). The teacher then moved to ask another question (reinforcement question) (line 3) to make sure that the student did not answer the question by guessing. After providing correct answer (line 4) the teacher praised the student (line 5) and repeating the students answer for confirmation (line 5\&6). 
The teacher provided both positive and negative feedback. Positive feedback was an indicator that the student answered correctly and a motivating tool to encourage the student and other students to participate in class interactions and therefore receive encouragement and praise. The table below shows type of feedback and examples for them.

Table 1: Types of feedback

\begin{tabular}{|l|l|}
\hline Type of feedback & Examples \\
\hline Positive feedback & $\begin{array}{l}\text { Good job, excellent, bravo, thank you, } \\
\text { very good, high five, brilliant }\end{array}$ \\
\hline Negative feedback & $\begin{array}{l}\text { That's not nice, stop doing this, do not } \\
\text { do that, }\end{array}$ \\
\hline
\end{tabular}

Students received reinforcement when answering correctly. However, in case they did not provide correct answer, the teacher dealt with that in three ways. Firstly, the teacher grouped mistakes and addressed them in front of class at the end of lesson. In this sense, the teacher avoided criticizing those who made mistakes to save face and minimize any discouragement that might happen. The following transcript illustrates how the teacher addressed mistakes at the end of lessons.

$$
\begin{array}{ll}
\text { Extract } 4.10 \\
1 & \text { T: Ok guys... I noticed some of you have difficulties in the use of } \\
2 & \text { countable nouns and quantifiers.... countable nouns are nouns that } \\
3 & \text { you can count like one apple two apples... ok... uncountable } 4 \\
4 & \text { nouns are nouns that you can not count for example water and } 5 \\
5 & \text { juice. Countable nouns can be singular or plural... we form plural } \\
6 & \text { by the adding 's' to noun... uncountable nouns do not take 's' } 7 \\
7 & \text { plural... now we use 'some' before plural countable nouns and } 8 \\
8 & \text { before we can uncountable nouns... say some water, some apples } \\
9 & \text { but we can not say some apple ... why ... because it is singular } 1 \\
10 & \text { noun ... ok .... }
\end{array}
$$

(CO5, M39).

In previous extract, the teacher noticed that students misuse quantifiers like some. So, at the end of lesson, the teacher briefly explained the use of quantifier some. In this sense, the teacher avoided criticizing students or rejecting their answer. The teacher spoke to whole class to save face of those who made mistake and to minimize the misuse of quantifier at later stages.

Secondly, the teacher corrected spontaneous mistakes after repeating students' responses. The following transcript illustrates how the teacher corrected the mistake after repeating the student's answer.

\section{Extract 4.11}

1 S1: Use digital thermometer measure temperature ear.

2 T: It is called tympanic thermometer... Ok... We use tympanic

3 thermometer to measure ear temperature. Ok... One more time....

4 tympanic thermometer. Now... digital thermometer is used to measure 
5 temperature through mouth... under the arm... or rectally... What is the

6 name of thermometer S1?

7 S1: Tympanic thermometer.

8 T: Excellent S1.

$(\mathrm{CO} 3,26)$.

The teacher corrected the mistake after repeating the student's answer (line 2). The teacher did not criticize the student and the teacher did not reject the answer. In this sense, the teacher supported the student's confidence and lessened any chance of future discouragement or demotivation (line 2). The teacher corrected the student's answer by repeating what he has said without any criticism (line3, 4). Also, the teacher explained the difference in route between types of thermometers (line 4,5) and asked the same student to answer a question again (line 5) to make sure he understands the difference and praise him after he answered correctly. The teacher then praised the student for answering the question correctly (line 7). Moreover, the teacher paused eight times in this extract which is shown with three dots (...) above. The teacher also uses comprehension check 'ok' (lines 2,3) to make sure every students understands the difference between types of thermometer.

Thirdly, the teacher offered clues and ask related questions to allow selfrepair and a chance to students to discover their mistakes and correct themselves. However, the teacher rarely employed this strategy. The teacher explained that in one of informal chats that this strategy requires more time and sometimes students are misdirected and deviated from original question and only high levels can go on in this kind of talk. The teacher said: "It is better to use the time for drilling and practicing of material" (IC, 4). The following transcript illustrates how the teacher guided the student to the correct answer.

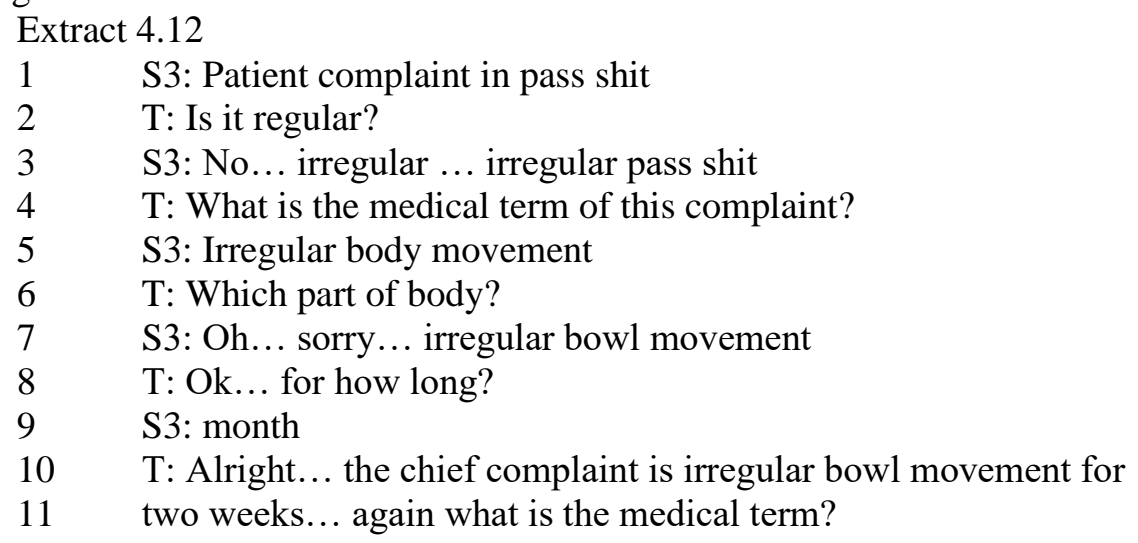

(CO10, M 13)

The teacher did not reject the student's answer. However, the teacher asked another question to give the student a clue about the answer (line 2). The teacher then asked the student for the appropriate medical term for the patient's complaint (line 4). The student made a mistake (line 5) by saying body instead of bowl in answering the teacher question. The teacher asked the student another question to direct him to correct answer (line 6) and allow the student for self-repair. After 
being guided by the teacher's questions, the student was able to offer complete answer (line 7). The teacher then confirmed the answer (line 10) and then move to reinforce the answer by asking for repeating the term (line 11).

Negative feedback was mainly used by the teacher in response to disruptive behaviors such as side talk during the teacher speech. Also, the teacher frequently used negative feedback when the students talk or interrupt their colleagues while they respond to questions or during presenting their ideas. The teacher frequently used statements and imperatives like (that is not nice of you; you should listen to your colleagues talking; show some respect to your colleagues; imagine they speak while you talk, I am sure you will not like it) to express his anger to such behavior and to establish a respectful climate for classroom talk and interactions.

Errors are treated in this study as linguistic errors such as grammatical or as content errors which relate to factual errors. Content errors were found to be more important to teacher as he corrected them after repeating student response or giving clues to guide student to correct answer. Linguistics errors are not dealt with in most cases by teacher. The teacher chose to ignore basic grammatical mistakes to allow student speak at length and increase students' talking time (IC4). The following extract about explaining medication illustrates how the teacher ignored grammatical mistake.

\section{Extract 4.13}

1 S: Swallows capsules with water... No exceed four capsules day.

2 T: Yes... Brilliant... Good job!

(CO9, 27).

The teacher praised student (line 2) even though he made grammatical mistakes in imperative form (line 1) by saying swallows instead of swallow, negative particle no instead of do not and in indefinite article by not saying $a$ day. Accepting sentences like this and ignoring the grammatical mistakes encourage all students to talk and take active part during lessons. The teacher in previous example did not repeat what the student said and chose to praise him without criticizing or rejecting.

\subsection{The use of metaphor}

The use of metaphor in classroom talk is another characteristic of teacher talk. Metaphors are a rhetorical tool that constitutes the figurative function of language. Metaphor was mainly used by teacher to provide an image of himself and his role. The teacher also used metaphor to explain a concept or even a word which is unfamiliar by comparing it with something familiar to students in order to make the concept or word simpler. In the following transcript, the teacher compares stethoscope with a technological device to link the word with something familiar to students that can facilitate their learning.

Extract 4.14

1 T: Stethoscope is headset. Doctors use stethoscope to listen to

2 internal body sounds.

3 S1: Teacher, the headset for listen music?

4 T: Yes, that's true. But, stethoscope is used to listen to heart 
5 sound, chest sound .... Ok. Once again... stethoscope.

(CO3, M26).

In previous extract, the teacher compared stethoscope with headset which is quite familiar device to all students. Also, the teacher offered clarification on the use of stethoscope (line 1,2,4,5). Moreover, the teacher repeated the word stethoscope 4 times to make it comprehensible for all students.

Also, the teacher used metaphor to create a sense of humor in classroom and make students laugh especially when they start to lose concentration. As observed, it was an effective method to get their attention back and it is not only something funny, but also important to facilitate learning and encourage students' talk. The following transcript illustrates how the use of metaphor inspires the students' talk.

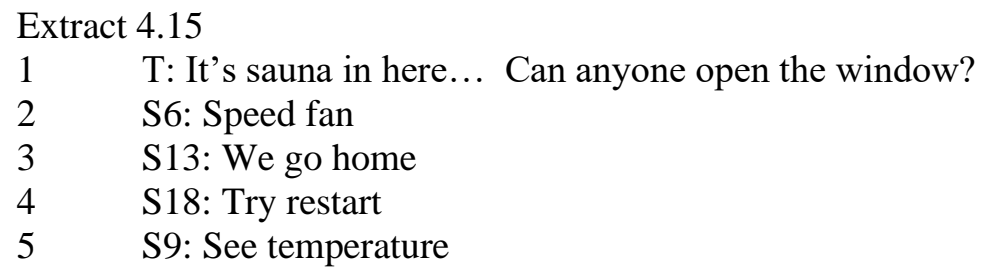

(CO4, M37).

After saying this, students laughed because opening window will worsen the room temperature. Then the students offered solutions to the teacher (lines 2, $3,4,5)$. Interestingly, the teacher got students' attention back nicely without asking them directly to concentrate, invited students' talk as they offer solutions and he continued his lesson as it supposed to be.

Another example appeared in one lesson in which the teacher was talking about healthy food and healthy eating habits. Students reacted to metaphor by laughing and at the same time got the idea which advices them not to eat late at night especially fatty food. It is noted that metaphor encouraged students' insights and talk. The following transcript illustrates how the use of metaphor inspired classroom talk.

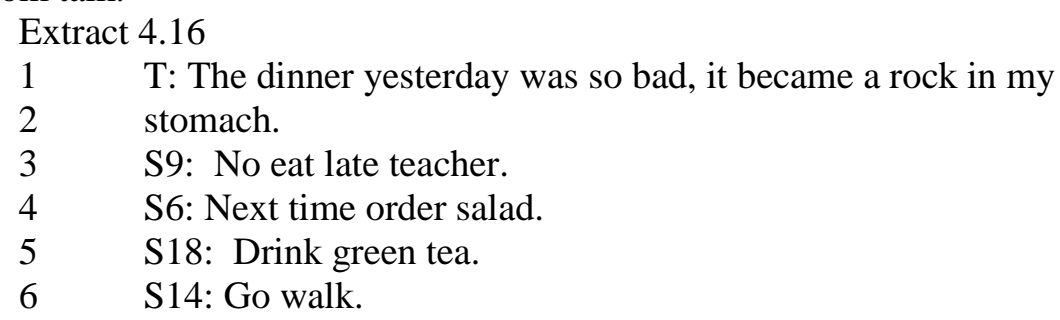

(CO6, M18).

The use of metaphor in previous extract (line 1) invited the students to talk and offer ideas for the teacher which is evident in (lines 3, 4, 5, 6). The students comprehended the metaphor and therefore were able to offer suggestions and ideas. Their ideas were reasonable and show that they have good knowledge regarding the subject. Familiar topics accounted for more students' talk in classroom. 
As said earlier, teacher talk is an important element in classroom interaction and it influences students' learning. The percentage of each of the characteristics of teacher talk is shown in the table below.

Table 2: Characteristics of teacher talk

\begin{tabular}{|l|l|}
\hline Teacher Talk & Percentage \\
\hline Praise and encouragement & $9.48 \%$ \\
\hline Jokes & $0.39 \%$ \\
\hline Accepting and using students' ideas & $18.9 \%$ \\
\hline Instructions and modelling & $22.4 \%$ \\
\hline Feedback & $33.6 \%$ \\
\hline Metaphor & $0.89 \%$ \\
\hline
\end{tabular}

\section{Discussion}

As indicated in the literature review, teacher talk dominated classroom discourse to offer a comprehensible input for the students. This finding of this study is in line with Winarti (2017), Hollo and Wehby (2017), and Lucero and Rouse (2017). The teacher talk was found to influence students' learning of target language which is reflected in the students' turns and which was confirmed through observation. Moreover, language in praise of students was a common teacher's practice which was seen to guide students' involvement and taking parts in lessons. Despite the buzz for learner-centered approach where the students should take the biggest portion in classroom talk, the findings of this study reveal that the teacher took the biggest portion of classroom talk. The reason behind the teacher's taking the biggest portion of classroom talk can be linked and explained in relation to the students' level and the type of material at hand. The students' proficiency level determines the quantity and the quality of talk. As explained earlier in this section, the language of medicine is new to students and the students have no prior knowledge regarding it. The teacher is considered the main source of medical language in classroom and therefore need to equip the students with an input which they can use and communicate. Interestingly, the students' talk tends to be more towards the end of lessons and they developed autonomy in learning toward the end of course. This explains that the teacher has no intention to take the biggest portion of classroom language, but the situation demands him to take more time than the students to offer an input which the students can use during interaction throughout the course. Autonomous learning and ability to construct meaning and express self were developed in the course as a result of comprehensible input offered to the students which is in line with the principles of student-centered approach. Failure to offer a comprehensible input on the other hand hinders students' learning and result in less interaction and communication and less meaning construction and reconstruction in classroom.

This is consistent with Krashen's (1985) input theory, in which the students are expected to use the target language after receiving an amount of language or input. Accordingly, the students in this study were able to use the target language 
after the negotiated and modified input from their teacher. Therefore, the teacher should establish and encourage moments to exercise intended language and consequently elevate the students' level. This finding aligns with Krashen (1985), Winarti (2017), Lucero and Rouse (2017), Goh, Yusuf and Wong (2017), AlZahrani and Al-Bargi (2017), and Irmayani and Rachmajanti (2017).

\section{Conclusion}

The teacher talk can be described as having high frequency of self-repetition, using jokes and metaphors, encouraging and praising students, and accepting and applying students' ideas. The teachers offered feedback in several ways that made students aware of mistakes and not affecting their motivation. The teacher praised correct answers, used students' ideas and negotiated mistakes to reach correct ones. The students were also given chances for self-repair. The characteristics of teacher talk accounted for input comprehensibility, avoiding confusion and encouraging participation. The linguistics characteristics of teachers' talk induced more involvement and possibilities for incidental language learning. The teacher's proper classroom management served as ideal atmosphere for learning and a motivation tool to students' participation and engagement. Failure in accommodating talk to the students inhibits classroom learning and students' noticing and recognition of target language.

Omar Ali Al-Smadi

Faculty of Languages and Communication

Al-Ghad International Colleges for Applied Medical Sciences, Saudi

Arabia.

Email: omarsmadi91@yahoo.com

Radzuwan Ab Rashid

Universiti Sultan Zainal Abidin, Malaysia

Dheif Allah Hussain Falah Altamimi

English Language Department

Tabuk University, Saudi Arabia 


\section{References}

Ab Rashid, Radzuwan. (2018). 'Dialogic reflection for professional development through conversations on a social networking site', Reflective Practice, 19: 105-117.

Ab Rashid, Radzuwan, Shireena Rahman and Kamariah Yunus. (2017). 'Reforms in the policy of English language teaching in Malaysia'. Policy Futures in Education, 15 (1): 100-112.

Abu Shakra, Zena. (2005). 'Exploratory feedback and student interaction'. International Journal of Arabic-English Studies, 6: 147-160.

Allwright, Dick and Kathleen Bailey. (1991). Focus on the Language Classroom: An Introduction to Classroom Research for Language Teachers. Cambridge: Cambridge University Press.

Al-Smadi, Omar and Radzuwan Ab Rashid. (2017). 'A theoretical review of classroom discourse'. International Journal of Academic Research in Progressive Education and Development, 6 (3): 164-173.

Al-Smadi, Omar and Radzuwan Ab Rashid. (2019). 'Teacher talk in an English for medical purposes classroom'. Trends in Social Sciences, 1 (1): 57-63.

Al-Zahrani, Mona and Abdullah Al-Bargi. (2017). 'The impact of teacher questioning on creating interaction in EFL: A discourse analysis'. English Language Teaching, 10 (6): 135-150.

Behtash, Esmail and Tayyebeh Azarnia. (2015). 'A case study of teacher talk time and student talk time in an Iranian language school'. International Journal of English Language, Literature and Translation Studies, 2 (3): 274-285.

Bell, Nancy. (2013). 'Responses to incomprehensible humor'. Journal of Pragmatics, 57 (1): 176-189.

Chaudron, Craig. (1988). Second Language Classrooms: Research on Teaching and Learning. Cambridge, MA: Cambridge University Press.

Dzuganova, Bozena. (2002). 'A brief outline of the development of medical English'. Bratislavske Lekarske Listy, 103 (6): 223-227.

Ginting, Siti Aisyah. (2017). 'The importance of opening moves in classroom interaction'. Advances in Language and Literary Studies, 8 (6): 7-11.

Goh, Pauline, Yusuf Qismullah and Kung Wong. (2017). 'Lived experience: Perceptions of competency of novice teachers'. International Journal of Instruction, 10 (1): 21-36. 
Hollo, Alexandra and Joseph Wehby. (2017). 'Teacher talk in general and special education elementary classrooms'. The Elementary School Journal, 117 (4): 616-641.

Irmayani, Irmayani and Sri Rachmajanti. (2017). 'Lexical features of teacher talk in English classrooms in senior high schools'. Dinamika Ilmu, 17 (1): 59-70.

Jarad, Najib. (2009). 'The effect of communicative competence on classroom interaction'. International Journal of Arabic-English Studies, 10: 219-236.

Krashen, Stephen . (1985). The Input Hypothesis: Issues and Implications. London: Longman.

Long, Michael. (1996). The Role of the Linguistic Environment in Second Language Acquisition: Handbook of Research on Second Language Acquisition. New York: Academic Press.

Lucero, Edgar and Megan Rouse. (2017). 'Classroom interaction in ELTE undergraduate programs: Characteristics and pedagogical implications'. Colombian Applied Linguistics Journal, 19 (2): 193-208.

Reddington, Elizabeth and Zhang Waring. (2015). 'Understanding the sequential resources for doing humor in the language classroom'. Humor, 28 (1): 1-23.

Sankar, Gokul and Suresh Kumar. (2016). 'English for employability and employment'. International Journal of English Literature and Culture, 4 (6): 100-103.

Sinclair, John McHardy and Malcolm Coutlhard. (1975). Towards an Analysis of Discourse: The English Used by Teachers and Pupils. London: Oxford University Press. 
Szendroi, Ildikó. (2010). 'Teacher talk in the ESP classroom: The results of a pilot observation study conducted in the tourism context'. WoPaLP, 4, 3958.

Winarti, Winarti. (2017). 'Classroom interaction: Teacher and student talk in international class program (ICP)'. KnE Social Sciences \& Humanities, (2017): 220-226

Zaid, Safawati, Zakaria Hassan, Radzuwan Rashid and Salina Ismail. (2016). 'An examination of negotiation process among ESL learners in higher institution'. International Journal of Applied Linguistics and English Literature, 5 (6): 228-234. 